\title{
COMMUNICATIONS
}

\section{VALUE OF ORTHOPTICS IN THE TREATMENT OF SQUINT*}

BY

\author{
A. A. DOUGLAS
}

Birmingham

SCIENTIFIC progress in the mid-19th century seemed to leave the stage set for a more comprehensive study of squint than had hitherto been possible. Wheatstone discovered the stereoscope in 1838. Brewster described his model in 1849. Between 1855 and 1865 appeared the great works of Donders and von Helmholtz, and Dieffenbach had made his communication on the results of treatment by operation to the Académie des Sciences in 1840; however, it was certain fortuitous events in the life of a young Parisian that determined the raising of the curtain.

Émile Louis Javal (1839-1907) was a member of a gifted Jewish family in affluent circumstances. Of considerable mathematical ability, and with a scientific bent, he qualified as a mining engineer with a view to taking over the management of some mines with which his family was concerned. This for a time he actually did and not without success; but an interest in ophthalmology had been stimulated earlier in his life. What in later years he was to call the " massacre of the internal recti " reached its apogee during his boyhood. One of the victims was Javal père, whose convergent squint was operated on by Desmarres. The result was a divergence which produced that peculiarly disturbing effect on the beholder which led Critchett (1855) to describe such patients as a "kind of haunting spectral vision ". The young Emile was greatly distressed, and became so prejudiced against the operation that when his sister Sophie became affected by the family squint he determined to attempt treatment by another method. In 1863 he commenced to use the stereoscope, then a fashionable toy in the drawing rooms of both hemispheres, and in 1864 published his experiences in a paper entitled Une nouvelle méthode pour guérir le strabisme.

An admiration, amounting to hero worship, which he conceived for von Graefe (whom he had met when the great man was consulted by his father) probably influenced the young Javal in his decision to abandon his career as a mining engineer for the study of medicine. This he did by entering the School of Medicine of the University of Paris in 1865. His thèse inaugurale, presented in 1868 and awarded a silver medal, was entitled Du strabisme dans ses

* Received for publication July 6, 1951.

Abridged version of the Middlemore Prize Essay, 1949. 
applications à la théorie de la vision; it was based on a study he had made of cases of " false projection" which he had observed prior to operation and diagnosed by means of the stereoscope.

Having decided on a new career he threw himself into it with characteristic thoroughness. His chief interests were physiological optics, the physiology of vision, and the problems of strabismus. Translator of Donders and von Helmoltz, he was familiar with seven languages and read most of what pertained to his special subjects in all of them. During his professional life he devoted a large proportion of his time to the most minute and painstaking study of cases of strabismus. Fortunately for an oculist who took up " orthoptics" as a career his financial position was such that he required no payment for his services. Stereoscopic exercises, supervised by himself, continued sometimes for years, and he recounts how the shorthand notes of these sessions in a single case would fill a larger volume than his Manuel du strabisme (1896), which contains 370 closely printed pages. While he thus disregarded time, as an admirer of Benjamin Franklin he never wasted it. His interests were manifold and he left an impression on all he touched. Astigmatic himself, he was among the first to recognize the clinical importance of this defect. His auto-observations and the relief he experienced on wearing cylindrical lenses are described on page 20 of the Manuel-a relief all the more welcome since it enabled him to continue his studies instead of, as he had been advised, giving them up to become a farmer. His labours to produce an ophthalmometer for clinical use are well known, and developments of the instrument he produced in collaboration with Schiötz are in use to this day.

Over his later life glaucoma cast its dark relentless shadows; but in spite of eventual blindness he continued to give to the world the fruits of a rich experience and a well-filled mind. Having spent the greater part of his life in the study of vision, he devoted his later years to the lack of it, and in 1903 published Entre aveugles, a book still in demand by those for whom it was written.

His Manuel dy strabisme, his most important work, deals with that branch of clinical research to which he was most passionately attached. $\mathrm{He}$ characteristically postponed its publication until 1896 in order that his ideas and conclusions might mature. It is not surprising that one of his ability, industry, and intellectual integrity should have produced a book that has strikingly survived the test of time. Though naturally since then instruments have become more flexible and better finished, they are in essence the same as those he designed and used, and the broad principles of treatment he laid down are followed to-day. Indeed it is perfectly true to say that were Javal to visit an orthoptic clinic at any English or American centre at the present time he would find nothing which was not entirely familiar, or that a few moments would not make so. What would surprise him would be to find the stereoscopes in gleaming rows, each with its attendant vestal, while 
the ophthalmometer, which he regarded as at least as important a contribution to clinical ophthalmology, rusted in some neglected corner.

\section{ORTHOPTICS SINCE JAVAL}

Orthoptic training had a certain vogue in the earlier part of the 20th century, and, though the results were generally looked upon as disappointing, it had its supporters, including Parinaud (1899) and Rémy (1906) in France, whose methods have been continued and elaborated by Cantonnet and Filliozat (1934), Priestley Smith(1898), who introduced "fusion tubes" the predecessor of the amblyoscope, Maddox (1898), and Wells (1912). Worth (1903). becoming convinced that in the "fusion faculty" (words which though employed by Javal have come to be associated with Worth's name) he had the key to the problem of strabismus, undertook fusion training with great enthusiasm, and at least to begin with claimed great success from the method if used in sufficiently young children. His book had a wide circulation in English-speaking countries. That it became more widely known than the more detailed and perhaps more thoughtful work of Javal was doubtless due to the fact that there is no English translation of the latter; at any rate much interest was aroused by "Worth's Squint", and orthoptics as practised in England and America may be said to be in the direct line of descent from that work. Worth's well-known classification of the grades of binocular vision are the daily currency of the orthoptic department.

Probably the most significant development of the last 30 years has been the rise of the orthoptic technician. Orthoptic training is such a time-consuming business that surgeons who engaged in it were forced to employ others, often a relation or a secretary, to continue the routine part of it. Such technicians were at first employed only in private practice, but a desire to extend the advantages of orthoptics to hospital patients led in the 1930s to the appointment of several of them to hospitals and local authorities. Since then a rapid development has taken place so that at the present time practically all ophthalmic hospitals and ophthalmic departments of general hospitals in Great Britain employ one or more orthoptists. This development has its advantages and also its dangers. The main advantage is the ease with which the surgeon may obtain a report on the binocular function of his patients, and thus save his own time. The main danger is that too large a share of the treatment of squint may be entrusted to the orthoptist, who, it must be remembered, has had only a minimum of scientific training. The orthoptist, though usually conscientious and enthusiastic, is apt to lack the broad outlook given by training in the basic sciences and a knowledge of morbid processes as a whole. The assessment of the results of treatment is difficult even for an experienced observer, and cases may continue to be treated uncritically in a routine fashion without much thought being given to the wider issues involved. Law (1938) went so far as to say that the practice of orthoptics had reached the position of a vested interest, and that only uncritical acceptance was needed to ensure its persistence irrespective of its excellence. 
Ophthalmic opinion is at present divided on two counts :

(1) The intrinsic merit of orthoptic training.

(2) The wisdom of allowing development to proceed along the present lines.

Most would agree that the orthoptic department has come to stay in some form or other, because of its value in diagnosis, in supervising occlusion, and in maintaining a closer liaison with the patient and his parents.

\section{What IS MEANT BY ORThOptic Training}

Javal clearly looked upon binocular vision as something learned, and upon the perfected function not as a concern of "centres" but as the result of activity of a diffuse sort involving the perceptual levels of the brain as well as afferent, coordinating, and motor neurones. It may be likened to an edifice effortlessly yet miraculously built up in the child on a foundation of corresponding retinal areas and simple sensori-motor reactions of a reflex nature. In cases of squint, though the edifice may not be destroyed, it becomes so warped and damaged that its restoration, if possible at all, is accomplished slowly and with difficulty. It is this restorative process that constitutes orthoptic training as Javal understood it. It might be described as a method which endeavours to teach, mainly by the use of the stereoscope, correct single binocular vision, in order that this may be used to induce the visual axes to maintain their correct relationship to one another. If training (if necessary with the aid of operation) fails to promote this correct relationship, then the acquired skill in binocular vision is not only useless, but probably doomed to extinction; if it succeeds it will constantly be reinforced by a sort of beneficent circle (Fig. 1).

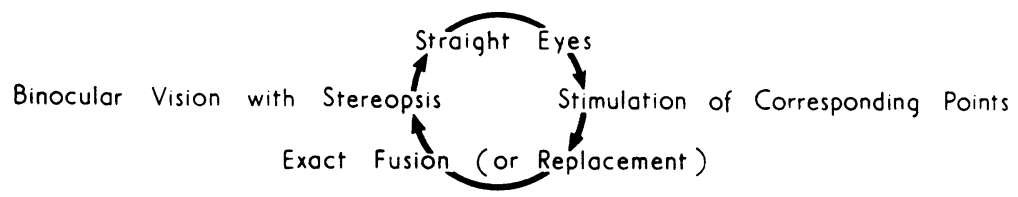

Fig. 1.

A corollary of this conception of binocular vision, well understood by Javal, is that, in the case of squints of early onset (say in the first year), the edifice is in such an early stage of construction (or the function so ill-learned) that restoration is usually impossible. In those of late onset, by which is meant after the 5th year, as a rule not much restoration is necessary, since the edifice is by then nearing completion and is certainly staunch and not readily damaged. In this realization that squint is essentially a disturbance of post-natal development, Javal differed from Worth, who, as is well known, saw it as a disorder proceeding from a defect of the fusion faculty, which he looked upon as an inborn ability present in different people in a higher or lower degree. Certain cases were incurable owing to a " congenital defect of the fusion faculty" -a statement which, in the words of Burian (1941), is more final than satisfactory. 
Javal's broad line of treatment is given on page 146 of his book as follows:

(1) To correct refractive errors.

(2) To correct suppression and produce diplopia.

(3) To obtain fusion at first in one position of the gaze and to extend it to all others.

(4) To consolidate the result and re-establish the correct relationship between accommodation and convergence.

La fusion des images doubles pour toutes les directions du regard, c'est la guérison du strabisme, he writes. In recent papers there is little inclination to differ much from his ideas and recommendations (Pascal, 1934; Goulden, 1935; Mayou, 1936; Shaad, 1938; Bielschowsky, 1939a ; Burri, 1942; J. E. Lancaster, 1943 ; W. B. Lancaster, 1944).

While orthoptic procedure cannot properly be held to embrace such methods of treatment as correction of refractive errors, occlusion, and operation, which are used by practically all surgeons who treat squint, the muscle exercises still used to some extent in orthoptic departments may be included in its sphere. Such gymnastics played no part in Javal's methods, as he specifically states, and their employment must be looked upon with the same sort of reserve as is maintained with regard to the exercises to improve vision so revealingly described by Huxley (1943). As Bielschowsky points out in an excellent review of the physiology of the ocular movements (1938), all the ocular muscles participate in producing every movement of the eye; Sherrington demonstrated that stimulation of a cortical centre for lateral movements caused contraction of contralateral agonists and relaxation of the antagonists. According to Hering's Law every motor impulse flows equally to both eyes. Selective exercises are thus impossible, and in any case extreme movements of dextro- or laevo-version are unphysiological; normally they are avoided by compensatory movements of the head, the eyes themselves seldom moving more than $12^{\circ}-15^{\circ}$ from the centre of the binocular field. In addition the strength of the extra-ocular muscles is greatly in excess of the demands made of them (W. B. Lancaster, 1941a).

\section{Estimates of the Value of Orthoptic Training}

Javal's personal experience of orthoptic training is unrivalled, and he had in addition, as his book abundantly shows, a knowledge of the problems of squint hardly added to since his day. His opinion on the role it should play in treatment must therefore be treated with great respect. There is no doubt that he began with a strong prejudice against surgery, but this he later relinquished completely, for not only did improvements in operative technique and the introduction of cocaine and general anaesthesia greatly reduce the danger and discomfort of the operation, but also he found that though he sometimes appeared to succeed in improving the binocular function of his patients he failed to affect the angle of squint to any significant extent in cases of permanent strabismus. He therefore recommended that operation be used to rectify the position of the eyes in cases of squint with a fixed element, and that training be employed to confer that which he thought surgery had not in its power--improvement in function. Though he retained his early faith that training could effect this improvement, he later began to doubt 
whether this offspring of his youthful prejudice and enthusiasm was fit to earn its keep in a practical and busy world in whose exacting marts physiological binocular vision is not in great demand. He somewhat ruefully recounts how when he first demonstrated his therapeutic methods to von Graefe the great man " as justly celebrated for his benevolence as for his professional merits " astonished him by saying, les gens ne sont pas dignes de tant de peines. The experience of a life-time convinced him that von Graefe was right, and quite apart from the fact that social and economic factors often render the process of re-education impossible, in difficult cases he considered the time and trouble involved in training to be beyond all reasonable measure, and to outweigh the benefits obtained.

Javal's conclusions are temperate and carefully considered. Since he pronounced them all shades of opinion have been expressed from the very enthusiastic, through all shades of scepticism, to the frankly derisory (compare, for example, Cantonnet and Filliozat, 1934, with Chavasse, 1939a, b). Conversation with colleagues indicates that a large majority hold, that while in a few cases a good result is apparently obtained, in the great majority the benefits conferred are not apparent. Discussion with orthoptists has revealed that many of them have misgivings as to whether the time they devote to treatment sessions is well spent. A really good result is looked upon as an occasion for general rejoicing even if the treatment has included operation.

After reviewing the English and American literature of the last 10 to 15 years the writer would say that qualified approval is the predominant attitude of ophthalmologists, though it is interesting to notice that three of the most prominent authorities in the field of muscle surgery, Bielschowsky, Jameson, and O'Connor, are quoted by Bressler (1936) as having sent personal communications to the effect that they considered orthoptic training to be of little value. Probably the concensus of opinion is that it is a useful addition to the well-tried methods of occlusion, correction of refractive errors, and operation.

The writings of those who support orthoptic treatment follow a remarkably constant pattern: epitomes are given of theories of binocular vision and the aetiology of squint ; instruments and targets for the stereoscope are described; a section is devoted to methods of procedure, including " tips " on personal methods; some case histories are related; and the results are described as "encouraging". When one seeks published results of controlled experiments which would enable a confident estimate to be made of the advantages of adding orthoptics to the therapeutic armamentarium against squint, the issue immediately becomes confused and difficult. This is freely admitted even by avowed supporters of the method (Wheeler, 1941; Shaad, 1938).

Series of cases, some with controls, have been published, but Chavasse, in a trenchantly-worded paper $(1939 \mathrm{~b})$, roundly declared that proof of the value of the stereoscopic method was still lacking:

It will be found that if the cases of alleged success are recorded with sufficient detail to permit of adequate analysis they are remarkably prone to fall into a class-intermittent and of small degree-which is obviously unsuitable for the evaluation of any method. 
If on the other hand the method of mass statistics is employed, one is apt to note the absence of adequate evidence that the controls, if any, deserve the title.

It must be admitted that there is much justification for such a criticism of the published results, for these contain many sources of fallacy probably more obvious to those who have themselves contemplated or attempted a similar task. The difficulties are in fact very great. In the following pages an attempt is made to estimate them, and to indicate the lines along which an enquiry, which is certainly needed, might be carried out :

(1) The number of factors at present thought to influence the outcome of treatment is so great that a very large series of cases and controls would be necessary.

(2) Standards of morbidity are very difficult to lay down, since many of the cases the surgeon must treat are in the occasional category and may never have been seen by him actually to squint. Yet these are the cases which give the best results when treated sufficiently early by correcting lenses.

(3) Standards of cure or recovery are equally difficult to decide upon. While only a few squinting patients in whom the defect has been constant for any length of time attain the perfection of binocular function possessed by the normal individual, larger numbers reach a standard which permits single binocular and clear vision for both near and distant objects, perhaps with the aid of glasses ; and in others, the binocular function, though poor in that the eyes are correctly aligned only for more distant objects, is not entirely without value. It is therefore wrong to set up a very high standard as was done by a group of British orthoptists (Lyle and Jackson, 1940), for then patients with straight eyes and quite good binocular function are lumped together as cosmetic successes with those with a permanent squint and no binocular function at all. It is equally wrong to adopt a standard (details of which will be found in Lyle and Jackson, third edition, 1949), which is obviously related not so much to a really useful degree of binocular function as to one which is fairly readily attainable by the methods of treatment at present in fashion. Ability to bar-read Jaeger 6 type with glasses, or Jaeger 12 without, is not of much value, if, as is usually the case, a squint is at once apparent if the child is confronted with a comic strip or a replica of Mickey Mouse.

If two groups of cases treated by different methods are to be compared-and this the only purpose of criteria of recovery-it would probably be best to adopt a system of marking. Certain standards would be decided upon arbitrarily, which would vary in the degree of binocular function and in the correct position of the visual axes-whether, for example, the axes are correctly related with or without glasses, or for near and distance vision. A mark would be allotted for each standard ; but even then it would be difficult to place the cases in the correct group, and the difficulties would by no means end here because of the following considerations :

(a) If much reliance is placed on subjective reactions and readings of instrumentsand it is impossible to avoid this-it is difficult to distinguish between correct binocular function and the ability to give a good performance on an instrument.

Control children, when tested on the synoptophore, cannot be expected to make such a good showing as children who have been tested on many occasions. In Maddox wing and rod tests and in Worth's lights the reading can very easily be varied by a complaisant and intelligent child, to suit the expressed or implied wish of the examiner.

(b) Obviously the most important criterion of cure of squint is that the eyes should be straight. The current suggested standard for discharge (Lyle and Jackson, third edition, 1949), which includes the

" ability to attain parallelism [sic] of the visual axes in all circumstances", appears to recognize this, but does not suggest how this important information may be 
obtained. It cannot be too strongly emphasized that measurements by the synoptophore are quite useless for this purpose. Presumably because of the nature of the stimuli supplied, children with normal eyes frequently give a convergent reading, which results either from the dynamic esophoric state of their age, or from the idea of nearness of the targets (instrument convergence). From such readings an erroneous assumption that a squint is present may be made. In the same way adults and many children after operation on the internal recti, may give a divergent reading when the visual axes, confronted with the normal panorama of distant and near objects, are correctly related. On the other hand, even children with permanent convergent strabismus may give a reading of zero or a small positive or negative quantity. If the squint is of recent onset and the (latent) binocular co-operation good, an erroneous assumption that recovery has taken place may be made, when in fact, the visual axes are so out of alignment that binocular single vision is impossible.

Photographs and the Hirchberg mirror test are useful but are open to the objection that they do not reveal small angles of deviation and do not relate to function. Most accommodative squinters readily learn the useful social accomplishment of " holding misty", that is, relaxing accommodation more or less completely and allowing the eyes to assume a correct or nearly correct position ; but under these circumstances clear vision for distant objects is sacrificed and acuity for near objects does not reach a useful level.

W. B. Lancaster (1941b) says :

Among those whom we regard as most competent to judge, there is agreement that the cover (screen) test is the most reliable method of estimating the direction, and, with prisms, the amount of deviation, in both heterophoria and heterotropia.

Detailed accounts of how this test may be employed have been given by Duane (1917) and more recently by White (1944). In order to detect the presence and direction of a squint and to measure the angle it is used by the writer as follows :

The patient is placed in a good light and asked to fix in concentrated fashion one of the letters of (usually) the $6 / 12$ line of the test types from which he is $6 \mathrm{~m}$. distant. The right eye is covered and the left watched for movement. Both eyes are uncovered for a short time and then the left is covered and the right watched for movement. If the eyes are normal there is absolutely no movement of either eye to take up fixation when its fellow is covered. If a squint is present, when one or other eye is covered its fellow moves to take up fixation, except in the uncommon and usually obvious cases of eccentric fixation. The angle of squint may be measured by placing a suitable prism or prisms in front of one eye to neutralize the movement. After some experience the observer will be able to estimate the prism required with considerable accuracy by looking on the eye as the needle, as it were, of some recording instrument, and judging the amplitude of its excursion. The test is repeated at $30 \mathrm{~cm}$., using as fixation object a small replica of an animal or bird. An indifferent object such as the point of a pencil is unsuitable since it provides a poor stimulus to accommodation. (Javal remarks on the value of small type for this purpose, saying that it acts as a talisman to reveal the presence of a squint, not noticed as a rule, but always present when the eyes are used for reading or other fine close work.) Further repetitions of the cover test can then be made in any desired direction of the gaze.

(4) In comparing the results of different forms of treatment it is necessary to give each one adequate time to bear fruit according to its nature. In accommodative squint and in some other types, improvement may take place spontaneously up to the age of 14 or more, on account of the natural diminution in hypermetropia, the swing from eso- to exophoria, and changes in the shape of the orbits. Instead of orthoptic training being used to regularize accommodation and convergence, the glasses may gradually be reduced in strength, a process which may take years. When the position of the eyes has been corrected by operation a high grade of binocular vision may be attained after a considerable interval without any training at all. The writer has observed this on many occasions. The total time it would be necessary to devote to an enquiry of the kind contemplated would thus fall not far short of 14 years. 
(5) Particularly in the case of occasional divergent squint it is difficult to be sure that constant urging, or a little judicious bullying supplied by the orthoptist, and not fusion training may be the cause of the improvement. A parental slap whenever the deviation is seen has been known to sharpen a child's appreciation of whatever sensory data are concerned with awareness of the deviation. It would therefore seem reasonable to give the control cases some " exercises" (not fusion training) to neutralize this factor.

\section{Examination of the Published Results in the Light of the Foregoing}

Among the more widely quoted reports on the efficacy of orthoptic training are those of Pugh (1936), Guibor (1934), Bressler (1936), Travers (1936), and Berens (1937). While these and other studies contain much that is interesting and give useful indications of how a properly controlled scientific experiment might be run, none of them provides proof of the value of orthoptics. It is even doubtful if they succeed in adducing evidence in its favour. The chief criticism that can be levelled against them is that of Chavasse-that there is insufficient evidence that the controls deserve that title. In some of the papers no particulars at all are given about them, nor is any statement made that they are unselected samples comparable with the treated group in such vitally important respects as age, age of onset of squint, incidence of amblyopia and anomalous retinal correspondence. Where any particulars of the controls are given, it is only too obvious that they and the treated cases are not comparable in these respects.

Other criticisms which apply to some though not to all of the papers are:

(1) The numbers are too small.

(2) It is not clear that the controls had had adequate preliminary treatment by occlusion and the wearing of glasses.

(3) Evidence is lacking that the controls had been given sufficient practice with the stereoscope to enable their performance on this instrument to be compared.

(4) The control group included a high proportion of children under five, too young to give performances on instruments comparable with those of the older treated group.

(5) The method of deciding whether or not the eyes were straight is not stated. (Possibly the synoptophore was used.)

\section{Scope of Present Investigations}

If orthoptic training is to have a permanent place in the treatment of squint it must prove its usefulness not only in the hands of the medical specialist working under experimental conditions with selected material, but also in those of the technician to whom the task is delegated, working under ordinary out-patient conditions with the type of children most in need of treatment-those from the primary schools, not particularly intelligent, and often lacking in concentration.

The purpose of this section of the essay is to attempt to assess the results obtained by the routine work of two orthoptic departments, both dealing with large numbers of patients. Only cases of comitant squint in children 
have been considered, since these constitute the main bulk of the problem of treatment. The orthoptic departments concerned are:

(I) That of the Eye Department of a Children's Hospital.

(II) That attached to an Eye Hospital.

The material from these sources has been treated in somewhat different ways. The main investigation is concerned with the results obtained in the first department (at the Children's Hospital). It was decided to adopt this course because :

(1) Patients attending a Children's Hospital form a more representative group including those of early onset-before the third birthday.

(2) The writer had more intimate experience of these patients since they were all under his care. He was able to make follow-up examinations in nearly every case, and had personally performed the operations.

The cases studied had been recently under treatment and not necessarily finally discharged, since special examinations could be carried out, doubtful points cleared up, and orthoptists consulted while the particulars were still fresh in their memories. It was also thought that in such cases the time factor would be less disturbing and the actual influence of training more clearly seen. The results from the second department (at the Eye Hospital) are dealt with in a somewhat different manner for reasons which will be explained below.

Assessment of Results of Training in Department I.-A series of 178 cases has been studied, the latest of which began training in March, 1948. The remainder are consecutive, working backward from that date. All are cases of comitant squint in which training had been considered worth a trial and comprise an unselected sample of the therapeutic work of the department.

Classification of Material.-Apart from other classifications, squinting patients can be divided into two groups (Javal, 1896) :

(1) Those who have single binocular vision in some positions of the gaze.

(2) Those who have not.

Such a division is of capital importance from the point of view of prognosis, especially when orthoptic training is to be employed. It was therefore decided to classify the cases of convergent squint into two groups.

GROuP 1.-Those reported to have straight eyes while wearing glasses before training. (Since a variable period had elapsed between the examination by the surgeon and the beginning of training a deterioration had occurred in a few cases, so that a deviation was present even while glasses were worn. These cases are nevertheless included.)

Group 2.-Those cases in which a squint was present even while glasses were being worn. Because of the influence on prognosis a further subdivision was made of this second group :

2(a) Those who reacted according to retinal correspondence.

2(b) Those who reacted according to anomalous correspondence.

Method of Procedure.-The records of each case were carefully scrutinized in order to estimate what changes took place as a result of training. Such changes may be in (a) binocular function, or (b) angle of squint. Since training can only 
produce improvement in $(b)$ through $(a)$, special attention was paid to $(a)$, and the phrase " binocular status" is used to describe the state of binocular function at any given time as regards presence of simultaneous macular perception, fusion, fusion amplitude, stereoscopic vision, etc. Summary" cards were made out for all the cases and such particulars were entered thereon. It soon became obvious that a bald statement about the binocular status before and after training was of little value in assessing the result of training for the following reasons :

(1) The binocular status at the initial examination was seen to vary widely from that at a session soon after, in the sense that considerably improved readings were obtained. There will be general agreement that such apparent improvement merely indicates that the child has greater facility in the use of the instrument, and understands better what is required of it. Such a conclusion was reached by Travers (1936) who took the information from the child as reliable at the fifth session. A similar method has been adopted by the writer who uses the term "diagnostic session" for that session of the first five which gives the best performance.

(2) Other factors, such as the passage of time, or the prescription of new glasses, complicated the issue.

(3) Since synoptophore measurements of the angle of squint cannot be relied on, special examinations were necessary to ascertain this. At these the cover test was used.

In the original essay, in order to give the reader an idea of the evidence on which conclusions were based, a series of tables was compiled from the summary cards giving information amounting to a short history of each case. These tables are so long that they cannot be included in this shortened version.

\section{Results of Training}

Group 1. Straight with glasses before training.-This group comprises 92 patients ( 53 per cent.), mainly of the fully accommodative type, but also including a few with a fixed element of recent origin, and probably some in whom emotional factors played a preponderating role. Of the 92 cases it was possible to make a follow-up examination in 81 ; the information regarding them is summarized in Table I and further classified in Table II.

TABLE I

RESULTS OF TRAINING IN GROUP I

\begin{tabular}{|c|c|c|c|c|c|c|c|c|c|c|c|c|c|c|c|c|}
\hline \multirow{2}{*}{$\begin{array}{c}\begin{array}{c}\text { Type of } \\
\text { Test }\end{array} \\
\text { Result }\end{array}$} & \multicolumn{3}{|c|}{ S.M.P. } & \multicolumn{4}{|c|}{ Fusion } & \multicolumn{5}{|c|}{$\begin{array}{l}\text { Fusion Amplitude* } \\
\text { (79 cases with fusion) }\end{array}$} & \multicolumn{4}{|c|}{$\begin{array}{l}\text { Stereopsis } \\
\text { ( } 78 \text { cases) }\end{array}$} \\
\hline & 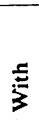 & & 嵒 & 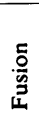 & 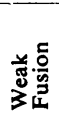 & 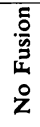 & సٓ & $\begin{array}{l}8 \\
0 \\
0\end{array}$ & $\begin{array}{l}\overline{8} \\
0 \\
0 \\
\text { ż }\end{array}$ & $\stackrel{\check{0}}{z}$ & 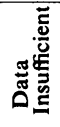 & 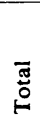 & $\stackrel{\underline{z}}{3}$ & 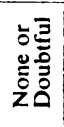 & 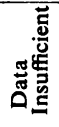 & $\frac{1}{5}$ \\
\hline $\begin{array}{l}\text { Before } \\
\text { Training }\end{array}$ & 80 & 1 & 81 & 77 & 2 & 2 & 81 & 37 & 40 & 1 & 1 & 79 & 58 & 14 & 6 & 78 \\
\hline $\begin{array}{l}\text { After } \\
\text { Training }\end{array}$ & 80 & 1 & 81 & 79 & 0 & 2 & 81 & 37 & 39 & 1 & 2 & 79 & 65 & 11 & 2 & 78 \\
\hline
\end{tabular}

* Throughout the tables fusion-amplitude is given in terms of adduction range, $20^{\circ}$ or better being arbitrarily considered as good, less than this as not good.

TABLE II

\section{CLASSIFICATION OF GROUP I CASES ACCORDING TO DEVIATION}

(As found by Screen Test at Follow-up Examination).

\begin{tabular}{llllll|l}
\hline No deviation with or without glasses for near vision or distance & $\ldots$ & $\ldots$ & $\ldots$ & $\ldots$ & 14 \\
\hline
\end{tabular}

\begin{tabular}{llllll|l} 
No deviation with glasses for near vision or distance &. & $\ldots$ & $\ldots$ & $\ldots$ & $\ldots$ & 46
\end{tabular}

Deviation even with glasses for near vision and distance. (In some of these the deviation

\begin{tabular}{lllllllllll|l} 
was not constant) & $\ldots$ & $\ldots$ & $\ldots$ & $\ldots$ & $\ldots$ & $\ldots$ & $\ldots$ & $\ldots$ & $\ldots$ & $\ldots$ & 16
\end{tabular}

$\begin{array}{llllll}\text { Other cases (e.g. straight with glasses for distance but not for near vision) } & \cdots & \cdots & & \cdots & \end{array}$

\begin{tabular}{llllllllllll|l} 
Total &. & $\ldots$ & $\ldots$ & $\ldots$ & $\ldots$ & $\ldots$ & $\ldots$ & $\ldots$ & $\ldots$ & $\ldots$ &. & 81 \\
\hline
\end{tabular} 
Group 2(a). . Not straight with glasses before training and reacting according to retinal correspondence.-This group comprises 38 patients with a fixed element, but in many there is also an accommodative element.

(i) Fifteen patients who at the time of the investigation had had no operation. Binocular function before and after training is shown in Table III.

TABLE III

RESULTS IN GROUP $2(a$ i)

\begin{tabular}{|c|c|c|c|c|c|c|c|c|c|c|c|c|c|c|}
\hline \multirow{2}{*}{$\begin{array}{r}\text { Test } \\
\text { Result }\end{array}$} & \multicolumn{4}{|c|}{ S.M.P. } & \multicolumn{4}{|c|}{ Fusion } & \multicolumn{3}{|c|}{$\begin{array}{l}\text { Fusion Amplitude } \\
\text { (cases with fusion) }\end{array}$} & \multicolumn{3}{|c|}{$\begin{array}{c}\text { Stereopsis } \\
\text { (cases with fusion }\end{array}$} \\
\hline & 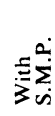 & 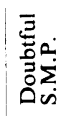 & $\dot{Z^{\prime}}$ & 䒿 & 采高 & 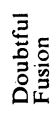 & Z嵒 & $\stackrel{\pi}{0}$ & $\begin{array}{l}Z \\
8 \\
0\end{array}$ & $\begin{array}{l}\overline{0} \\
0 \\
0 \\
0 \\
\mathbf{Z}\end{array}$ & 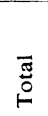 & $\stackrel{5}{3}$ & 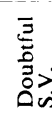 & 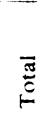 \\
\hline $\begin{array}{l}\text { Before } \\
\text { Training }\end{array}$ & 11 & 1 & 3 & 15 & 9 & 1 & 5 & 15 & 5 & 4 & 9 & 8 & 1 & 9 \\
\hline $\begin{array}{l}\text { After } \\
\text { Training }\end{array}$ & 11 & 1 & 3 & 15 & 10 & 0 & 5 & 15 & 7 & 3 & 10 & 7 & 3 & 10 \\
\hline
\end{tabular}

(ii) Twenty-three patients who at the time of the investigation had had operations. Binocular function before and after training and operation is shown in Table IV.

TABLE IV

RESULTS IN GROUP $2(a$ ii)

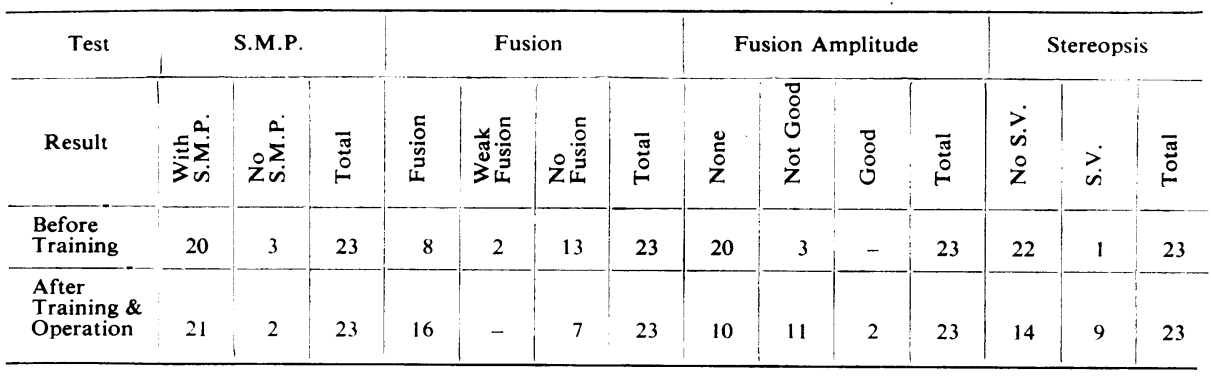

In the patients of Group 2(a ii) in whom a considerable improvement in function took place an attempt was made to assess the relative parts played by training and operation (Table V).

\section{TABLE V}

PARTS PLAYED BY TRAINING AND OPERATION IN GROUP 2 (a ii)

Major part played by operation (binocular function greatly improved immediately after)

Major part played by training (binocular function improved slowly, apparently as a result of training)

Both played a part

Total 
All the cases in Group 2(a) were also classified according to the presence or otherwise of deviation after training (or after pre-operative training in the case of the operated group) (Table VI).

TABLE VI

DEVIATION IN GROUP 2(a) AFTER PRE-OPERATIVE TRAINING

\begin{tabular}{cccccccccccc|r}
\hline $\begin{array}{l}\text { Deviation still present } \\
\text { No deviation }\end{array}$ & $\ldots$ & $\ldots$ & $\ldots$ & $\ldots$ & $\ldots$ & $\ldots$ & $\ldots$ & $\ldots$ & $\ldots$ & $\ldots$ & $\ldots$ & 37 \\
\hline Total & $\ldots$ & $\ldots$ & $\ldots$ & $\ldots$ & $\ldots$ & $\ldots$ & $\ldots$ & $\ldots$ & $\ldots$ & $\ldots$ & $\ldots$ & 38 \\
\hline
\end{tabular}

Group 2(a ii) has also been classified according to the presence or absence of deviation with glasses after operation (Table VII).

TABLE VII

DEVIATION IN GROUP 2 (a ii) AFTER OPERATION AND TRAINING

\begin{tabular}{|c|c|c|c|c|c|c|c|c|c|}
\hline No deviation with glasses & . & . & & .. & & . & & $\ldots$ & .. \\
\hline Deviation with glasses $\ldots$ & .. & .. & .. & .. & .. & .. & .. & . & . \\
\hline
\end{tabular}

Group 2(b). Not straight with glasses before training, and reacting according to anomalous correspondence.-The synoptophore was the instrument used for the diagnosis of this anomaly. There are 37 cases in the group, of which three had no pre-operative training. The results of pre-operative training on binocular function in the remaining 34 are shown in Table VIII. All three patients in whose case a change to retinal correspondence took place continued to squint.

TABLE VIII

EFFECT OF PRE-OPERATIVE TRAINING ON BINOCULAR FUNCTION

IN GROUP 2(b)

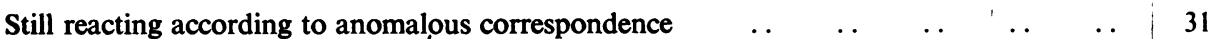
Change to retinal correspondence

Total

At the time of the investigation fourteen of the patients who had had training had also had operations followed in most cases by training. The results of training and operation are shown in Table IX.

\section{TABLE IX}

\section{EFFECT OF OPERATION AND TRAINING IN 14 CASES FROM GROUP 2(b)}

Still reacting according to anomalous correspondence

Straight eyes with an inferior grade of binocular vision

Developed retinal correspondence before post-operative training began, \begin{tabular}{llll|l}
$\ldots$ & $\ldots$ & $\ldots$ & 5
\end{tabular}

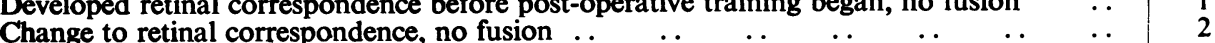

Had no post-operative training but now reacts according to retinal correspondence

Total 
The five cases with an inferior grade of binocular vision were studied in an attempt to assess the relative parts played by operation and training (Table $\mathrm{X}$ ).

TABLE $X$

PART PLAYED BY TRAINING IN 5 CASES FROM GROUP 2(b)

Training played no part ..

Training played minor part

Training played major part

Too difficult to assess

Total

Group 3. Divergent squint.-Table XI shows the results of training in eleven cases; in one case improvement appeared to follow operation.

TABLE XI

RESULTS IN GROUP 3

\begin{tabular}{|c|c|c|c|c|c|c|c|c|c|c|c|c|c|c|}
\hline \multicolumn{2}{|l|}{ Test } & \multicolumn{3}{|c|}{ S.M.P. } & \multicolumn{3}{|c|}{ Fusion } & \multicolumn{3}{|c|}{$\begin{array}{c}\text { Fusion } \\
\text { Amplitude }\end{array}$} & & \multicolumn{3}{|c|}{ Stereopsis } \\
\hline Result & & $\sum_{\dot{s}}^{\dot{0}}$ & $\begin{array}{l}\sum_{i}^{\circ} \\
\dot{0} \\
\dot{0}\end{array}$ & ॠ & 氙 & 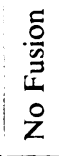 & $\underset{0}{0}$ & $\begin{array}{l}7 \\
0 \\
0\end{array}$ & 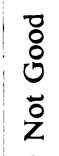 & 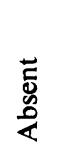 & 吾 & $\vec{i}$ & $\begin{array}{l}\dot{r} \\
\dot{z} \\
\dot{Z}\end{array}$ & 퓸 \\
\hline $\begin{array}{l}\text { Before } \\
\text { Training }\end{array}$ & . & 9 & 2 & 11 & 8 & 3 & 11 & 0 & 5 & 3 & 8 & 2 & 9 & 11 \\
\hline $\begin{array}{l}\text { After } \\
\text { Training }\end{array}$ & . & 9 & 2 & 11 & 8 & 3 & 11 & 2 & 6 & 0 & 8 & 3 & 8 & 11 \\
\hline
\end{tabular}

AsSessment of Results of Training in Department II.-An examination was made of the records of 100 consecutive cases of comitant squint in children and adolescents discharged from the orthoptic department of an Eye Hospital. The intention was to present a sample of the work done in the department, not to arrive at conclusions regarding the results of treatment of varieties of squint, although these are referred to later in the essay.. The changes which took place in the binocular status of the patients is set out in Table XII.

TABLE XII

RESULTS OF TRAINING IN 100 CONSECUTIVE CASES

No change in binocular status

Improvement in fusion amplitude (without operation)

\begin{tabular}{llll|} 
Improvement in fusion amplitude (apparently mainly as a result of operation) & $\ldots$ & $\ldots$ & 10 \\
Change from anomalous to normal correspondence (without operation) & $\ldots$ & & 3
\end{tabular}

\begin{tabular}{llll|l|l|} 
Change from anomalous to normal correspondence (after operation) & $\ldots$ & $\ldots$ & $\ldots$ & 3
\end{tabular}

Stimultaneous perception elicited

Insufficient data

Total

$\cdots \quad \cdots$

$\cdots \quad \cdots \quad 2$


As in the cases from the Children's Hospital, the diagnostic session method was used as a base line from which to estimate improvement in binocular function as a result of training. The total number of training sessions involved is 4,061 .

The end-results of treatment as given in the Orthoptic Department's records is shown in Table XIII.

TABLE XIII

END-RESULTS OF TREATMENT (RECORDS OF ORTHOPTIC DEPARTMENT)

\begin{tabular}{|c|c|c|c|c|c|c|c|c|c|c|c|}
\hline $\begin{array}{ll}\text { "Cured" " } & \text {. } \\
\text { "Cosmetic" } & \text { " Refused" } \\
\text { " Ceased to attend "; }\end{array}$ & $\begin{array}{l}\cdots \\
\cdots \\
\cdots \\
\cdots\end{array}$ & $\begin{array}{l}\cdots \\
\cdots \\
\cdots \\
\cdots\end{array}$ & $\begin{array}{l}\cdots \\
\cdots \\
\cdots\end{array}$ & $\begin{array}{l}\cdots \\
\cdots \\
\cdots \\
\cdots\end{array}$ & $\begin{array}{l}\cdots \\
\cdots \\
\cdots\end{array}$ & $\begin{array}{l}\cdots \\
\cdots \\
\cdots \\
\cdots\end{array}$ & $\begin{array}{l}\cdots \\
\cdots \\
\cdots\end{array}$ & $\begin{array}{l}\cdots \\
\cdots \\
\cdots\end{array}$ & $\begin{array}{l}\cdots \\
\cdots \\
\cdots \\
\cdots\end{array}$ & $\begin{array}{l}\cdots \\
\cdots \\
\cdots \\
\cdots\end{array}$ & $\begin{array}{r}17 \\
58 \\
9 \\
16\end{array}$ \\
\hline Total & .. & . & .. & . & . & .. & . & $\ldots$ & . & . & 100 \\
\hline
\end{tabular}

It is interesting to examine the records of the fourteen cases discharged as cured by orthoptic methods without operation in the light of Chavasse's criticisms of the published results already quoted. They are classified in Table XIV.

TABLE XIV

\section{CLA5SIFICATION OF CASES CLAIMED AS CURED BY ORTHOPTIC METHODS}

Accommodative squint straight with glasses before training

Alleged accommodative squint, presumably occasional, no record of $\ddot{\text { deviation ever }}$

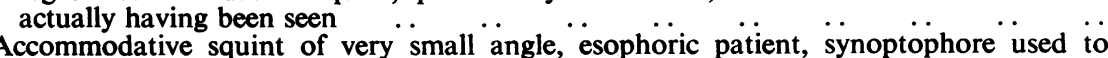

Accommodative squint of very small angle, esophoric patient, synoptophore used to measure pre-training angle

\begin{tabular}{lllllllllll|l} 
Occasional divergent squint & $\ldots$ & $\ldots$ & $\ldots$ & $\ldots$ & $\ldots$ & $\ldots$ & $\ldots$ & $\ldots$ & $\ldots$ & 5
\end{tabular}

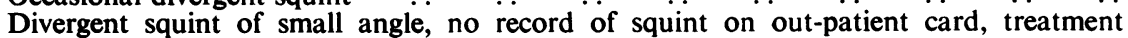
recommended for amblyopia

Total

..

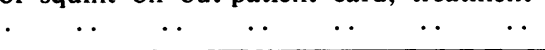

All three patients claimed as cured, whose treatment included operation, are recorded as having had fusion at zero almost immediately after the operation.

Additional Evidence from Other Sources.-Particulars were compiled of the results of examination of children at local authority clinics. The records had been kept with a study such as the present one in mind, and the 98 children qualified for inclusion in the following way :

(1) All had been seen to squint by an ophthalmic surgeon.

(2) All had reached the age of at least 9 at the time of a special examination in $194 \%$.

Of these 98 children, 42 were found to have had orthoptic training and 56 to have had none, for various reasons (although the surgeons concerned were in the habit of recommending training in all cases).

The two groups, trained and untrained, are compared in only one respect, whether or not the eyes were straight for near and distance vision with glasses. This was decided by the cover test performed by the writer (Table XV).

TABLE XV

DEVIATION IN TRAINED AND UNTRAINED GROUPS

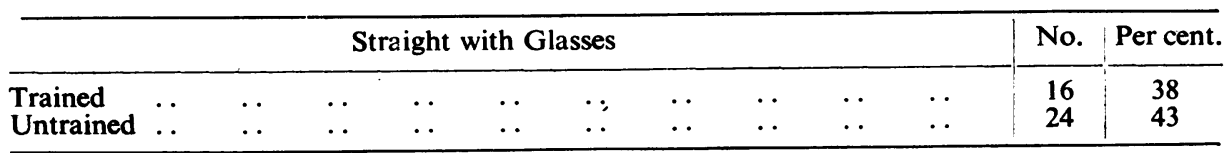


Not much stress can be laid on these figures, since the groups are small and, for other reasons, not strictly comparable. The untrained group, for example, may include less severe cases which the parents did not think necessary to have treated by orthoptic methods. One significant fact emerges, however, which clearly shows the hand of the orthoptic department on the trained group. There were only seven eyes in 42 trained cases with vision of $6 / 18$ or less, as against 22 eyes in 56 untrained cases. Needless to say this is a matter of the greatest importance.

Out of curiosity the records were studied of 23 pre-school children, all of whom had been examined in local authority clinics during a year, in order to estimate the effect on such cases of treatment by glasses alone. Of the 24 patients, so far as could be judged by the screen and mirror tests, ten ( 40 per cent.) were straight with glasses.

\section{Discussion of Results and TheORETICAL Considerations}

It is difficult to discuss the treatment of squint without entering into questions of aetiology, development, and progress, as well as the reactions to dissociation; but such theoretical considerations have been kept down to the minimum necessary to support the writer's arguments and define his point of view.

Javal distinguished between the partie fixe and the partie variable of squint, the first as a rule amenable to surgical and the second to optical treatment. Cases of predominantly accommodative type often include a fixed element, and the predominantly fixed an accommodative element. In favourable cases the partie fixe is zero and correction of the refractive element alone may be sufficient to restore the correct relationship of the visual axes for both near and distance vision, so that the physiological ideal of bimacular stimulation is constantly operative during waking hours. This is a highly desirable state of affairs, for it usually means, if the hypermetropia is moderate in amount and the patient an infant, that the normal reduction in the hypermetropia along with judicious under-correction will result in the cure of the squint when correct habits of vision have been established. Such a consummation is by no means rare and the earlier glasses are prescribed the more probable it becomes.

Accommodative SQuint.-In cases in which the fixed element is zero, there must be a constant rain of normal stimuli, for many hours daily far surpassing in colour, interest, intensity, motion, and infinite variety, those provided by the stereoscope. What then, it may be asked, is the purpose of duction training in these cases? The binocular status of the majority is fairly high at the commencement of training. Perhaps it should be possible to improve it by increasing the fusion amplitude especially as regards adduction; but experience shows this to be very difficult and it was not in fact achieved to any exteht in the cases studied (Table I). Some orthoptists say that the figures do not give a true picture of the position, and that improvement takes place in other more subtle ways, not lending themselves to formal recording. They instance an increased smoothness of movement, small but significant 
improvements in visual acuity, or diminution in suppression, all of which in a measure contribute to the perfection of the fusion faculty; and all this may be so, though it is difficult to prove. What does seem certain, in the writer's opinion, is that there is a fairly well-defined sub-group of the accommodative type in which attempts to improve the fusion amplitude and to break down suppression meet with even less success than in the usual variety. The cases in this sub-group are characterized by having perfectly straight eyes for distant vision with glasses, but a convergent squint, more or less pronounced, whenever near vision is attempted. They are referred to by Costenbader (1947) as atypical. To all appearance such children are unable to see at all clearly during near vision without squinting. They can usually be taught to " hold 'misty" and to bar-read large type-an accomplishment of which the practical value may be doubted. If, however, one of the small replicas of animals used by the writer is held $30 \mathrm{~cm}$. from the eyes of a child affected with this type of squint, and his interest stimulated perhaps by asking him if he can " see the little eyes" he will appear to make an effort, easily appreciated by the observer, and one eye will deviate inwards more or less strongly. Since monocular accommodation is usually found to be normal it would appear that there is a disorder of the involuntary reflexes which control the association between convergence and accommodation. These have been discussed in detail by Chavasse (1939a). Their involuntary nature can be demonstrated subjectively by the well-known experiment in which stereograms are superimposed and synthesized to form a unitary percept by exercising voluntary divergence or convergence (Fig. 2).
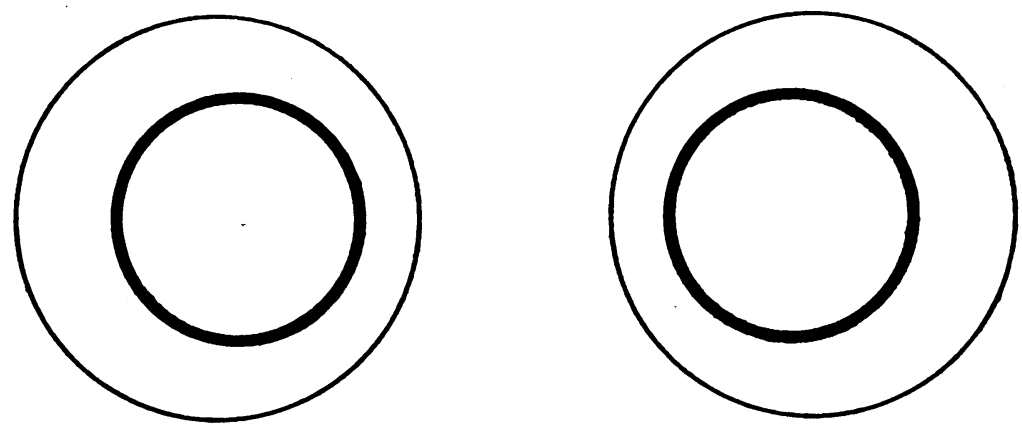

Fig. 2.-If the two diagrams are superimposed, by divergence of the visual axes, a stereoscopic effect is produced. If convergence is used the effect is of course pseudoscopic.

Introspection reveals that after superimposition the subsequent clearing is entirely beyond volitional control. The "mental effort" (Cantonnet and Filliozat, 1934) seems to consist more in a passive waiting for reflexes to take command than in any active process.

The child with atypical accommodative squint, therefore, finding that the involuntary reflexes have failed him, falls back on voluntary accommodation to secure the necessary definition. Voluntary accommodation being always 
accompanied by over-convergence the definition is secured, the price paid being a convergent squint. The ensuing diplopia is apparently easily neutralized by a facultative suppression that rapidly becomes deep.

Apart from duction training, orthoptic treatment may be directed to attaining a correct relationship between accommodation and convergence. That the two can readily be disengaged from one another in the normal individual under more or less artificial conditions (use of prisms, lenses, or stereograms) is well known. These methods can be used in accommodative squint and it is not usually a difficult matter to teach what the orthoptist calls "control"; by which is meant the ability to keep the visual axes correctly related to one another for near vision and distance, though almost invariably at the expense of clear definition. The patient may also be taught to maintain fusion on the stereoscope while progressively stronger concave lenses are placed before the eyes, or even to do this "off the instrument ", to demonstrate his prowess in "control " by performing correctly various exercises on the diploscope, and so on. There is, however, no exercise yet devised which will enable the orthoptist to maintain objective control while the patient does what is really necessary, namely, adjusts accommodation with the greatest nicety to suit any given amount of convergence, or vice versa. It can only be hoped that by producing certain artificial conditions which enable convergence and accommodation to be dissociated, those reflexes which will make easier the attainment of the nice adjustment necessary are facilitated. There is no assurance that this hope is justified, and it may even be doubted whether the " binocular skills" taught are any more than binocular tricks with little application to casual seeing.

The writer's experience has been that if the accommodation-convergence relationship is upset, as it is in the type of squint described as "atypical accommodative ", no form of orthoptic training will rectify it ; and furthermore, in the type of squint referred to as "typical accommodative", in which the visual axes are correctly related in all positions of the gaze while glasses are worn but are convergent without glasses, it is very rarely possible by training to secure effortless and correct function with clear vision without glasses. Training to achieve this in any case demands more intelligence than the average child of 6 or 7 possesses; it must therefore be postponed until a later age (say 11), by which time the reflexes concerned may have passed through the labile phase. The later age is a critical one from the educational standpoint and parents do not so readily sacrifice the time for exercises. A gradual reduction in the strength of the glasses is a reasonable alternative which, though slower, is less troublesome.

In order to evaluate the method of treatment by glasses without any training a group of children who had had no orthoptic treatment was studied. The writer's idea was that it should be as nearly as possible comparable with Group 1 from the Children's Hospital. The cases were derived from school eye clinics and were seen and examined during the routine work. They qualified for inclusion as follows : 
(1) All had actually been seen to squint by an ophthalmic surgeon.

(2) None had had any orthoptic training.

(3) All were reported at least once as having been "straight with glasses".

By chance the observers were the same as those concerned with Group 1. Thirty-seven children who qualified in these respects were collected and examined by the screen test for the presence and amount of deviation (Table XVI).

TABLE XVI

CLASSIFICATION OF UNTRAINED GROUP OF ACCOMMODATIVE CASES

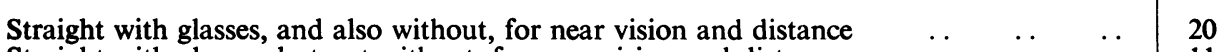

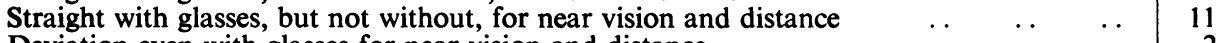

$\begin{array}{llllllll}\text { Deviation even with glasses for near vision and distance } & \ldots & \ldots & \ldots & \ldots & \ldots & 2\end{array}$

\begin{tabular}{llll|l} 
Other cases (e.g., straight with glasses for distance but not for near vision) & $\ldots$ & $\ldots$ & $\ldots$ & 4 \\
\hline
\end{tabular}

Total

To anticipate the criticism that binocular function might not be good in these cases an attempt was made to have as many as possible examined in Orthoptic Department I. The parents of twelve children responded to the request for a special examination. The binocular function proved to be good in all cases except one in which strong suppression was the cause of the deficiency.

The two groups (Group 1 and the series just mentioned) are small, and not strictly comparable, so that no final conclusions can be drawn, except perhaps that the advantages of training in such cases are not obvious; and yet, with a few exceptions (for example, Roth (1947), who states that in one orthoptic clinic cases of accommodative squint are treated without exercises), articles or text-books on orthoptics claim that it is just such cases which provide its most striking successes. It has even been said that when patients are not given the advantages of training the apparent cure with glasses is never satisfactory. This statement must be challenged since it does not reflect the true state of affairs, and might even lead to a falling off in the sense of urgency to treat immediately with glasses all squinting infant hypermetropes, and nonsquinting too in the presence of a bad family history. This is the true floodtide of the affair, and its taking would lead to more improvement in the position than any other single measure.

Convergent Squint with a Fixed Element.-Although success in the treatment of this type of strabismus by orthoptic training, if the angle is not large, has been reported (Feldman, 1935; Travers, 1936; Pugh, 1936; Lyle and Jackson, 1940), others have expressed the opinion that success is rarely if ever attained. Chavasse $(1939 a, b)$ and Wheeler (1941) have already been quoted, and Hicks and Hosford (1935) came to a similar conclusion. Javal's procedure in unilateral cases was to employ occlusion until alternation was secured, and then to proceed as for alternating cases which, in his opinion, always required operation (p. 228). 
The classification adopted in this study was designed to render the distinction between permanent and pure accommodative types more clear cut. Reference to Table VI shows that only in one case reported as " not straight with glasses before training" was the deviation absent after training, and there is at least some doubt whether the squint in this case was not in fact occasional.

As Chavasse remarks, it is significant that duction training fails to abolish the deviation in the not very uncommon cases in which a comitant convergent squint follows monocular occlusion for an injury or after dealing with a tarsal cyst. In these cases, if in any, it should be effective, and yet it fails, even when carried out persistently and for long periods, in cases in which there is no disturbance of binocular function to speak of.

The improvement in binocular function in the cases which had no operation is certainly not striking (Table III), but on the other hand, when the binocular status of the operated group is considered at the beginning and the end of treatment (Table IV), the improvement is perfectly definite, the number with fusion being doubled and the number with fusion amplitude more than trebled, an outcome of operation well known to orthoptists and remarked on by Berens, Payne, and Kern (1935), Hicks and Hosford (1935), Bressler (1936), and several others, including Javal. The real difficulty is to decide in what measure training plays a part in the improvement-or if, indeed, it plays any part. Table $\mathrm{V}$ shows the results of an attempt to find an answer to this question, but the conclusions must obviously be very tentative indeed. However, of the eleven cases which showed improvement, it was so rapid after operation in four that training could hardly be involved in it; in the other seven it is of course quite possible that the improvement would have occurred without it, though its gradual nature pointed to the effect of training to a greater or less degree.

It may be that training is of use in adjusting small amounts of postoperative divergence or convergence. The child with a permanent squint of several years' duration, who has just had an operation, is left to the care of binocular reactions long disused and frequently overscored by abnormal ones. There seems to be no doubt that the change in the position of the eyes following operation ushers in a period of flux. This may be used by the orthoptist to re-awaken dormant functions and, in favourable cases, to demonstrate what normal vision means and how it may be used to retain the eyes in the correct position. The difficulty is to transfer any abilities thus acquired to casual seeing.

DIVERGENT STRABISMUS.-Eleven cases form too small a group to provide anything but a peg on which to hang preformed opinions, though in fact the results correspond with these to a great extent :

(1) In cases of occasional divergence quite good results appear to be obtained from training alone. This was observed in two of the cases from Department $I$, and follow-up examinations showed that the improvement was maintained. 
Certain reservations must however be made. The suppression in these cases is not easily abolished and diplopia is seldom established. The "feel" of the correct position of the eyes appears to come from other sensory data which the patients cannot explain. When regular training stops, the "feel" may be lost, and the writer's opinion is that the apparently good results are not due to fusion training, but may be achieved just as well by other methods, such as the parental slap already referred to or by milder forms of discipline. The patients with occasional divergence nearly always have good binocular function for near vision and appreciate physiological diplopia, but they react according to anomalous correspondence while one eye is diverging (Bielschowsky, 1939b ; Grant, 1945), and are not then aware of physiological diplopia. If operation is performed in such cases good results may be expected.

(2) Cases of constant divergence are not amenable to training. They are only amenable to surgical treatment if some convergence is present, and there are remnants of binocular co-operation, which is often the case on account of the relatively late onset of this type of squint, which allows the fusion faculty time to develop. In cases with poor binocular function, not only does training usually fail to arouse much sign of it before or after operation, but, even in the cases which appear to be satisfactory from the cosmetic point of view, there is a strong tendency for the divergence to return and increase in the course of time.

It is noteworthy that amongst the cases from Department I there was not a single myope and that there were only three out of thirteen from Department II. The divergent squint of myopes, as also the convergent variety, is disappearing on account of the almost universal use of correcting glasses for myopia from early childhood.

Orthoptics and Abnormal Retinal Correspondence.-Von Graefe (1854), who was one of the first to investigate the phenomena then referred to as " false projection", described them as obscure (Eine höchst dunkele Reihe von Erscheinungen). There is general agreement that they remain so.

In recent writings on the subject, it is the end-organ of vision, the retina, which has mainly been referred to. It is said that one macula becomes abnormally related to an eccentric area of the other retina so that each comes to possess an identical or similar directional value. Pugh (1936) wrote of a false localization spot, Travers $(1938,1940)$ of an eccentric retinal area having the same "local sign" as the fixing macula, and Chavasse of " secondary" retinal correspondence. Burian, in erudite and thoughtful papers (1939, 1941, 1947), also writes mainly in terms of the retina.

Although pathological and experimental evidence points to a rigid relationship between retina and cortex, Duke-Elder (1932) argues from the phenomenon of false macula that the correspondence of retinal points is not an anatomical peculiarity but a functional attribute, not rigidly determined but capable of development and alteration.

The emphasis on the retina in these and other writings leaves an impression, probably not always intended but nevertheless very wide-spread in orthoptic 
circles, that anomalous (or abnormal) retinal correspondence is analogous to normal in a fairly strict sense, a substitution for the normal by a reaction of essentially the same sort. Such a conception would imply that Nature had seen fit to provide against the contingency of a squint by supplying potential neuronic connections which would enable one fovea and its correlated elements to be linked with another group similar in magnitude and centred in any point in a very wide area of the other retina. The number of neurones required would be immense, the biological advantages which would accrue not striking. It seems unlikely that such neurones have been provided, for Nature's prodigality is not of that kind. Such a difficulty may be overcome by taking one of these convenient leaps across the gulf that separates matter from mind, and concluding that the modified relationship is achieved by "cortical activity" or is "at perceptual level ".

It seems probable that the tendency to look upon the two types of reaction as of the same sort has given rise to the forms of orthoptic treatment most in vogue at the present time, which depend upon binocular stimulation by alternate flashing or moving targets.

The phenomena were of great interest to Javal. In all justice to him it must be emphasized that statements to the effect that the recognition of their frequency and importance are of recent date are quite unfounded. He had begun the study of them and was able to make a diagnosis by means of the stereoscope before 1870 . In his book he emphasizes how commonly they are found, and indeed avers that alternating squint of early onset is always accompanied by "false projection". (This term, of the unsuitableness of which Javal was well aware, was of course introduced to describe that form of projection, correct if unphysiological, which becomes false or incorrect when the position of the eyes is changed by operation.) To the large section of $d u$ Strabisme devoted to the subject, the appreciative comments of Goulden (1935) apply with added force, and the section set aside for two observateurs distingués, who describe most minutely their subjective experiences as actual sufferers, is a unique document, and demonstrates very clearly that it is as difficult for a person with normal binocular vision to understand false projection as it is for one with false projection to understand normal vision.

Javal was not only interested in the subject for its own sake but was concerned to use the information acquired from the auto-observers, and, from the study of a great many other cases, to defend the theory of corresponding points and their innate nature against the onslaughts of those who, like Helmholtz upheld the two related theories known as the "empiristic theory" and the " theory of projections", which denied the existence of fixed corresponding points with innate directional properties. The phenomena of false projection supplied the protagonists of the last two theories with some obvious and useful ammunition, which Javal rather neatly converted to his own use when he expounded a theory to explain these phenomena without departing 
from a sound physiological basis. The essence of the theory might be stated much as follows:

When the targets appear to be fused at zero in spite of a convergent squint, in fact they are not. Each is seen in practically identical positions but only with regard to the patient's body ; the percept lacks precision.* This is most strikingly seen in cases after operation (e.g., when there is crossed diplopia after the correction of a convergent squint, the eyes being straight or still slightly convergent), when the patient may have no idea of the distance separating the images and may even be unable to say which is to the right and which to the left. This state of affairs contrasts strikingly with that found in physiological diplopia, when the relative distance of the double images is easily referred to a system of co-ordinates, the centre of which is the object of attention of the fixing macula.

Javal's conclusion was that, in cases of false projection (for which he suggested the term localisation par habitude de déviation), there is a new system of reaction depending on awareness of the position of each eye with regard to the body.

There is much to be said in favour of the theory. It violates no physiological principles laid down since the time it was suggested. That the position of the eye is compensated for in monocular projection there is no doubt. Whether the awareness derives from proprioceptive or other data is a theoretical matter about which the present writer does not presume to express an opinion. When the eyes are used together, one of them being deviated, it is retinal correspondence which produces diplopia of a well understood kind. If retinal correspondence were inhibited (a process no more difficult or easy to understand than other forms of inhibition), there seems no reason why each eye should not follow its own monocular projection and see objects in the same position. It has in fact repeatedly been suggested that such a form of binocular co-operation may exist in those mammals who possess a considerable binocular field but no convergence.

The results of the subjective cover test indicate that retinal correspondence is indeed inhibited in established cases of both alternating and monocular squint. In this test the fixing eye is covered, and when the deviating eye moves to take up fixation the patient is asked to indicate by a movement of the hand the direction in which the object fixed appears to move. In cases of occasional squint and in those of recent onset, the apparent movement is in the same direction as the movement of the eye (Positive reaction). This is what would be expected in retinal correspondence, the covering of the fixing eye being accompanied by momentary homonymous diplopia, so to speak. In established alternators, on the other hand, there is no apparent movement of the object (Negative reaction): This is also the type of response obtained in the cases of many older children with monocular squint, though occasionally their reaction is perverse, as was that of one of Javal's auto-observers;

* Even the tyro in the use of the synoptophore can hardly fail to notice this. The lion is put into the cage in calculating fashion. D. S. Mann (1943) very aptly quotes patients as saying that they seem to be "in different worlds". 
that is, the object fixed appears to move in the opposite direction to the eye. This may also be encountered after operation (White, 1944).

According to Javal's ideas, the purpose of anomalous correspondence in a biological sense is not so much to attain an analogue of single binocular vision as to secure reasonably accurate location of objects by the non-fixing eye. Thus in alternators, by rapid alternation of attention usually combined with suppression, either eye can take up vision either direct or indirect in any part of the field, no mistake in location being made since each eye follows its own monocular projection with compensation for position. It may be added that the negative subjective cover test elicited in such cases has an important significance, in that it would be intolerable for a free alternator with a multipartite field of fixation to be constantly aware of movement of the panorama.

Cases of monocular squint provide the examples of the classical reaction on the stereoscope with full adaptation to the angle of squint. One eye is habitually used for fixation, while the other, the secondary eye, is always used in indirect vision and can inform its owner correctly of the position of objects, when for example, as must frequently happen in ordinary use, part of the field of the fixing eye is obscured (in this connection the case of " Dr. W" as analysed by Javal is most fascinating). Thus, according to Javal, there is no real difference between the reaction in alternators and that in those with monocular squint. In the former it is alternating and latent, neither eye being used to project falsely more than the other. Suppression is of the facultative type. In the latter the reaction is fixed and obligatory, amblyopia is common, and central fixation wavering. When direct vision is attempted by the squinting eye mistakes in bodily projection may be made, since it is not accustomed to such conditions. The perverse reaction to the subjective cover test indicates that compensation for position on monocular projection has broken down, the interpretation of direction adopted being as if the position of the eye had not changed (e.g. as if still adducted in convergent cases). When an operation is performed which does not completely correct the deviation two images may be seen by the still slightly squinting eye, one pertaining to retinal correspondence and the other to monocular projection erroneously compensated. Thus can be explained the binocular triplopia which has not infrequently been recorded in such cases.

Verhoeff (1938) expounds a theory with some affinities to that of Javal and specifically denies that there is any retinal correspondence at all in cases now designated by the term " abnormal retinal correspondence". There is, he holds, in any given case, either retinal correspondence which need not be qualified by the term normal, or an alternative system followed by comitant squinters of all kinds which he calls anomalous projection.

The apparent absolute position of all images that reach consciousness from the squinting is determined by the monocular projection of this eye possibly assisted by the effects of not consciously perceived images while their apparent relative positions are judged from the point of view of the fixing eye. 
Burian (1947) rejects a theory similar to Javal's (which he ascribes to Hering) on the grounds that anomalous correspondence may be observed in extreme amblyopia. It is difficult to accept the validity of this objection since the amblyopic and deviating eye would still be able to inform its owner of the position of bright objects and lights.

The unanimity with which anomalous correspondence is accepted as a bar to the successful treatment of squint contrasts strikingly with the lack of it when the chances of securing a return to normal correspondence by orthoptic methods come up for discussion. Smith (1939) and J. E. Lancaster (1942) report almost uniform success, and Pugh (1936), Lyle and Jackson (1940), Hitz (1941), and Feldman (1941), are modestly optimistic. On the other hand, Travers (1936), Chavasse (1939a), and Campbell (1947) consider the results very poor, and no less an authority than Bielschowsky is reported by W. B. Lancaster (1941c) to have been discouraged when he gave the method a personal trial. The orthoptists in both departments with which this investigation is concerned share this pessimistic view, and a study of the case records shows their pessimism to be well founded. In Department I, reference to Table VIII shows that of 34 cases treated without or before operation only three reacted normally in the end. In Department II, out of sixteen cases, three reacted normally.

It was the fact that such poor results were obtained after so much painstaking effort that led the writer to go more deeply into theoretical considerations than this subject might seem to warrant.

There is a good deal to be said for the view that data of ocular position play a much more important part in the mechanism of anomalous correspondence that any modified retinal correlation, and that therefore it is illogical to attempt to re-awaken retinal correspondence by training, while the important abnormal positional relationship which is the cause of the anomalous reaction remains undisturbed. The stimulation of the maculae by dissimilar or even similar images, while the visual axes are convergent and no accommodation is taking place, is in any case bizarre.

Javal recommended operation in all cases to secure parallelism. In some this was successful without any further treatment; if not, he found it easier to extricate his patients from the paradoxical relationship than from the preoperative one, the absurdity of having to look to the right to see an image on the left or vice versa often proving of help in establishing normality. Such "proprioceptive reorientation" may be attempted before operation, but the striking effect of surgery in disposing the patient towards a return to normal binocular reactions (Table IX) leads to the conclusion that it is wise to take advantage of this labile phase and to reserve reorientative as well as the more usual methods of training until the post-operative period. In routine work therefore the aims should be:

(1) To secure alternation as early as possible in permanent strabismus.

(2) To perform carefully-planned operations to correct the deviation accurately.

(3) To attempt to consolidate the result by orthoptic training in suitable cases. 
Influence of Age of ONSET of SQuint on Results of OPERATION.-Since there is as yet no proof in the form of a large series of cases with adequate controls that the orthoptist is able to influence the result in cases of comitant squint subjected to operation, it is natural to attempt to explain the undoubted fact that in some cases almost perfect results in the physiological sense are obtained, while in others, no matter how meticulous the surgeon may be in the correction of refractive errors, the details of occlusion, the technique of operation, and the use of orthoptic methods, the ideal of correct binocular vision escapes him, although the result may be satisfactory cosmetically.

A great deal of discussion can be found in the literature about factors of bad prognostic omen; different authors have their bêtes noires, but these factors include : " essential" alternation, differences in height, persistent amblyopia, and anomalous retinal correspondence. This complicated position has been greatly simplified by Chavasse (1939a); few can fail to have been impressed by his arguments in support of his contention that squint is fundamentally a disorder of the binocular reflexes. Although possibly he rather overworks the terminology relating to the study of reflex action, nevertheless it is well suited to his purpose, and his use of it has led to the formulation of views which, though previously held by Javal and others, had to await the new branch of physiology originated by Pavlov for their clearer enunciation. Pavlov's writings (1910, 1927, 1935, 1928-1941) have had a profound influence on modern thought. Chavasse, by applying the ideas of Pavlov to the problems of squint, has laid ophthalmology deeply in his debt. His " modern" theory of squint may be restated ten years later somewhat as follows:

In man, while certain reflexes, usually old in the phylogenetical sense, are present at birth, even if birth takes place prematurely, others are slower to develop, and while under normal circumstances their genesis follows in fairly regular chronological order, they are in a sense conditioned, inasmuch as, if the environment falls short of the normal requirements, or if there are faults, congenital or acquired, in the organism itself, they fail to reach perfection to a greater or less extent. In the elaboration of reflexes of a more refined nature the critical period is young childhood - the first 5 years of life. As a result of the studies by Gesell (1923), Gesell and Thompson (1938), Gesell, Amatruda, Castner, and Thompson (1939), Gesell and many others (1941), and Gesell and Amatruda (1947), of large numbers of infants and young children, what they call the "normative" behaviour-pattern has been worked out in great detail and recorded month by month. It is true that after the age of 5 years elaboration and refinement continue, but the main pattern is woven in by 5 , and by 8 is more or less unalterably fixed.

These broad laws and generalizations apply to vision and binocular vision, and its process of development can be studied in the individual and in parallel fashion in the race, each step forward the child makes having its counterpart in the visual progress of the vertebrates from the comparatively simple arrangements found in fish to the refinement of man and the anthropoids. The acquisition of binocular vision may be looked upon as a learning process (Burri, 1942), its basis being the primitive reflexes of ancient lineage which underlie the relatively simple and 
constant ocular responses of a child of 2 or 3 months old. Progressively, however, as he grows older, not only is there an increasing network of neuronic connections but also, as he is subjected to a constant bombardment of diverse stimuli, the primitive responses become conditioned, resulting in a fixed behaviour-pattern by the time the period of reflex flux is ending, about the age of 6 . By 8 the critical period is past and the binocular reflexes may be said to be unconditionally fixed; so that after this age only gross anatomical lesions are capable of precipitating a deviation and causing vision to cease to be binocular. It follows that in cases of late onset, given the possibility of restoring the anatomical normal by, say, shortening a muscle or grafting the cornea, correct function will follow as a matter of course. If, however, a motor, sensory, or other obstacle to binocular vision precipitates a deviation before the learning process is complete, the result is its interruption, which must continue until the visual axes are restored to parallelism : so that a child who began to squint at $2 \frac{1}{2}$ and has a correcting operation at 6 might be expected to possess that degree of binocular co-operation characteristic of a child of $2 \frac{1}{2}$; moreover, since the learning process is nearly complete at 6 , in such a case little further progress could be expected. That is by no means the whole story, however ; for frequently after the onset of a squint a learning process proceeds but in a perverted fashion, so that, particularly in those of high adaptability, a whole series of compensatory reactions ensues, conditioned reflexes in fact, the conditioning factor being the incorrect position of the eyes. These abnormal reactions overscore the normal and may in their turn reach unconditional fixity.

These considerations lead to a suspicion that all the diverse factors held to be of bad prognostic significance in squint are ultimately traceable to two :

first and most important, the age of onset of the squint, second, the adaptability of the child.

The extreme importance of the first of these was well known to Javal, but it is remarkable how frequently statistics of squint are published without this vitally important information. The matter readily lends itself to simple statistical treatment and the following question may be asked. Given accurate correction of refractive errors and efficient treatment by occlusion, can the results of operation, so far as the attainment of single binocular vision is concerned, be related simply to the age of onset of the squint?

The writer has attempted to answer this with regard to a series of 214 cases of comitant squint operated on by him in the Children's Hospital in the years 1946-49.

Age at Operation.-In some cases the operations were performed at a later age than seemed desirable. This was owing to post-war conditions, particularly the influx of patients returned from evacuation to increase an already long waiting list. So far as possible the cases were dealt with in rotation.

While the age at operation varied between the two extremes of 3 and 12 years, a high proportion (73 per cent.) was between 6 and 10, the average age at operation being 7.7 years. This average age at operation was also calculated separately for two groups :

(a) Those who eventually achieved single binocular vision (55 cases).

(b) Those who failed to do so (159 cases).

In both groups the figure was 7.7 years, i.e., the same as the whole series. 
From these considerations, and in the light of a careful study of the individual case histories, the writer has concluded that in the series under consideration, the age at operation had little or no influence on the final result.

Results.-It is proposed to give in a later communication details of the methods of classification and of the standards employed. For the present only the results are given in Table XVII which also shows the average age at operation for each age group of onset.

TABLE XVII

RESULTS OF OPERATION AND TRAINING IN 214 CASES

\begin{tabular}{|c|c|c|c|c|}
\hline \multirow{2}{*}{$\begin{array}{l}\text { Age Group } \\
\text { of Onset }\end{array}$} & \multirow{2}{*}{$\begin{array}{l}\text { No. of } \\
\text { Patients }\end{array}$} & \multirow{2}{*}{$\begin{array}{l}\text { Average Age } \\
\text { at Operation } \\
\text { (years) }\end{array}$} & \multicolumn{2}{|c|}{ With Single Binocular Vision } \\
\hline & & & No. & Percentage \\
\hline $\begin{array}{l}0-1 \\
1-2 \\
2-3 \\
3-4 \\
4-5 \\
5-6\end{array}$ & $\begin{array}{l}48 \\
39 \\
69 \\
33 \\
15 \\
10\end{array}$ & $\begin{array}{l}7.2 \\
8 \\
7.7 \\
7.7 \\
8.4 \\
9.0\end{array}$ & $\begin{array}{r}1 \\
3 \\
13 \\
18 \\
10 \\
10\end{array}$ & $\begin{array}{r}2.1 \\
7.7 \\
19.0 \\
54.0 \\
66.0 \\
100.0\end{array}$ \\
\hline Totals & 214 & 7.7 & 55 & 26 \\
\hline
\end{tabular}

These results are quite clear cut, and show that the proportion of patients with single binocular vision rises from 2 per cent. for the age group of onset 0-1 year to 100 per cent. for the age group of onset 5-6 years. The same facts are

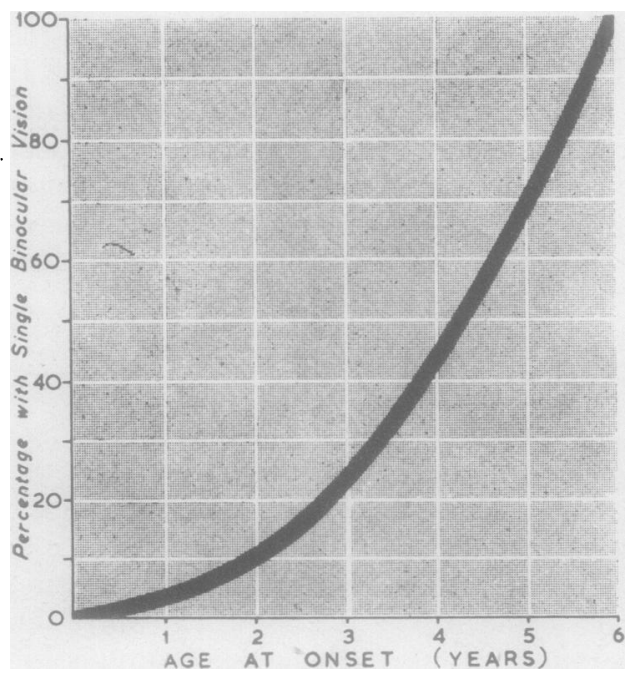

Fig. 3. presented graphically in Fig. 3.

The results of this investigation would appear to confirm the hypothesis that the age of onset is the most important factor in determining whether the result of operation will be good in a physiological sense. Since practically all the patients had had a trial of orthoptic training, which was attempted quite irrespective of the age of onset of the squint, so that it did not operate more in favour of one group than another, the results lead to the suspicion that the effects of training are more apparent than real, the orthoptists only eliciting reactions or measuring changes which have taken place or are about to do so.

Incidentally, it must be noticed that comparisons of the results of squint operations in different hands, or by different methods, are quite invalid unless the age of onset of the cases is taken into consideration. 


\section{CONCLUSIONS}

What has seemed most striking in reviewing the cases treated by orthoptic methods is the very large number in which prolonged training (amounting to sixty or more sessions) has been carried out without producing any significant change in the binocular status of the patients. It is natural to look for explanations of this seeming poverty of reward for so much painstaking work. The orthoptists concerned with both departments are conscientious to a degree, and the writer is greatly indebted to them for the careful way in which they have recorded their results. That so much time is spent on cases which fail to secure binocular vision is not their fault. Surgeons in charge of cases have had a feeling that all except the complicated ones of muscular anomalies of frankly congenital origin should be given a chance, and the result is that much of the orthoptist's work is experimental. The regrettable part is that this experiment, which has been going on for so long all over Great Britain, should have been so haphazard and uncontrolled. It would have been much more useful if the volume of work had been less but more exact, if different centres had undertaken to solve specific problems, and, most important of all, if controls had been introduced.

The question to which all who are interested in the subject will want to find an answer is this:

Is orthoptics fundamentally unsound as a method of treatment or is it wrongly applied at present?

In the light of modern theories of the acquisition of binocular vision as a learning process which takes 6 years to complete, it might very reasonably be held that much longer periods should be devoted to training than is at present the rule. Javal was certainly no facile optimist with regard to this. He held that even in cases treated by operation the time necessary to secure correct vision was roughly equal to the duration of the squint; a child who began to squint at 4 years and in whose case treatment was undertaken at 8 years might be finally cured by 12 years. In the spacious 1880s in Paris, Javal was able to recommend that a child with a squint should abandon her usual education and be given to the care of a governess instructed in stereoscopic exercises and bar-reading, who would supervise treatment under his direction. He was a hard task-master. Regarding stereoscopic exercises he says:

Exercises of this kind can be likened to the study of languages ; one can devote one hour daily to the study of a foreign language for 8 years without much result, which might easily be mastered by devoting 8 hours daily for a year, or better, 16 hours daily for 6 months. It seems that the result of work of this kind destroys itself during the time that is not devoted to progressing.

Judging from samples of correspondence to his patients he apparently looked on sixteen hours a day as a not unreasonable time to devote to the stereoscope. It must be emphasized that this was a first step only. Controlled reading, and exercises of extension without the stereoscope, had to 
be persisted in for long periods, constant precautions having to be taken to guard against suppression.

This sort of thing was possible, if extremely trying, for the beau monde of Paris in the late 19th century; it is completely impossible for the British working class or indeed for any other elass at the present time. The total number of sessions devoted to any individual patient has been greatly reduced, so that in Department I the maximum is about fifty where it used to be three hundred. The results are not considered to be inferior, and the change was made not mainly for reasons of expediency, but becaue the very large number of sessions did not give results commensurate with the trouble and time expended.

In another respect too, Javal's practice differed from that usually adopted at the present day. He only accepted for training patients who were docile, intelligent, and determined to recover. That this determination often amounted to obsession is obvious from the case histories. The out-patients of an average hospital cannot in the main be described as belonging to this category. Many of the children of 7 and 8 cannot read. The treatment often has to be abandoned or interrupted because of boredom. Only a minority are considered by the orthoptists to provide adequate co-operation, and a by no means negligible proportion is verging on mental deficiency. Javal certainly never intended that his methods of squint training should be used in such a manner or with such human material.

During the last 20 years or so, while interest in the subject has been growing, his book has never received the recognition it deserves, and the ground he explored and charted so carefully has been covered again and again by others, who failed to put his unrivalled experience to a profit, but in many cases reached the same conclusion-Les gens ne sont pas dignes de tant de peines.

Its tediousness, slowness, difficulty, and uncertainty are grave practical disadvantages of the orthoptic method which have always been recognized; but there are other objections which, though largely theoretical, are perhaps crucial and go far to explain its lack of success. The first of these is that its nature forbids its use in the formative years of very early childhood-the " first 5 years of life". By the time intelligence and docility are sufficiently advanced for its employment, the lability of the nervous system has receded to such an extent that any real facilitation of the binocular reflexes is hardly possible; though signs of binocular co-operation can often be elicited they are those characteristic of the age of onset of the squint and progress no further. The second objection, well supported by the theories of Pavlov, is that the constant repetition of meaningless stimuli inseparable from orthoptic training leads to inhibition, which rapidly spreads to the rest of the cortex unless very determined efforts are made by the patient to prevent this from happening, efforts which can hardly be expected from small children however resourceful the orthoptist may be in keeping their interest alive. 
As regards the cases, whether convergent or divergent, in which both operation and training have been employed, the very definite improvement which seems to occur as a result of the mere fact that the position of the eyes has been changed is an interesting finding of this study. Whatever the process that informs the organism of the position of the eyes with regard to the orbits it seems that approximate correctness acts in favour of binocular function (Adler, 1945). Alternatively, the interference with muscles and tendons and the change in position ushers in a period of lability. The writer has already expressed the opinion that this may be the fruitful time for the orthoptist who may then intervene and succeed in guiding the fluid reactions into the correct channels. This is however an impression only. Perfect physiological results may follow an operation even after an interval of a year with no training at all.

In cases of permanent strabismus, an alternative to operation plus training at the age of 6 or 7 years is early operation, which, if successful, will permit of a continuance of the binocular learning process during the plastic years of childhood. This Javal called the experimentum crucis. So convinced was he of the rightness of the procedure that he arranged for de Wecker to operate on his (Javal's) nephew at the age of 16 months. The child had a convergent squint of large angle which became occasional after operation and was later, Javal tells us, completely corrected by glasses and orthoptic methods. Javal has had many supporters in this conviction, including Chavasse, who called temporizing with occlusion and glasses until the age for fusion training " fiddling while Rome is burning " and allowing perversions to form so that they may later be diagnosed and treated. Many surgeons who have tried the method have expressed themselves satisfied with the results, but so far it is difficult to assess the degree of success attained, especially as regards the acquisition of single binocular vision.

Whatever the verdict of posterity may be on the value of orthoptics in treatment, there is no doubt about the magnitude of the contribution it has made, mainly in the hands of Javal, to our knowledge and understanding of the complicated binocular reactions in squint and the factors which influence prognosis. This, and not therapeutic success, was Javal's well-merited reward. The usefulness of orthoptics in diagnosis is not in dispute and the orthoptist is a most valuable member of the surgical team. Without this aid the surgeon, who as a rule has neither the time nor the temperament to undertake these exacting duties, works in the dark or by inference only; he cannot plan his operations with any confidence to fit the varying needs of every case. His work with squint, which can be so varied and interesting, becomes much less so.

The writer cannot help ending with a doubt whether it is in the best interests of squinting patients to expend great efforts to reach the oasis of single binocular vision, which so often proves to be an ever-receding mirage. Patients with a small angle of squint and no serious degree of amblyopia can 
seldom be found to admit that they suffer any inconvenience as a result. It may be objected that, never having experienced binocular vision, they do not appreciate what they are missing; but neither do those with normal vision appreciate what can be achieved by anomalous correspondence.

Everyone engaged in clinical work must, in his patients' interest, balance the reward likely to be obtained against the trouble, danger, and expense involved in treatment; and every case must be treated on its merits. No patient who has a reasonable chance of obtaining correct binocular vision as a result of an amount of training commensurate with its value to him need be denied it ; to pick out such cases, which are not common, is one of the most important functions of a well-run orthoptic department; but for the majority, in the present state of our knowledge, it is in the best medical tradition not to strive too officiously for perfection, but to be content with a functional and cosmetic condition that will satisfy the needs of the patient.

\section{REFERENCES}

Adler, F. H. (1945). Arch. Ophthal., Chicago, 33, 362.

BERENS, C. (1937). Amer. J. Ophthal., 20, 266.

PAYNe, B. F., and KeRN, D. (1935). Ibid., 18, 508.

BiELSCHOWSKY, A. (1938). Ibid, 21, 843.

(1939a). Ibid., 22, 38.

- (1939b). Ibid., 22, 145.

Bressler, J. L. (1936). Arch. Ophthal., Chicago, 16, 433.

BURIAN, H. M. (1939). Ibid., 21, 486. (1941). Ibid., 26, 626. (1947). lbid., 37, 618 .

BURRI, C. (1942). Ibid., $28,235$.

CAMPBELL, D. (1947). British Journal of Ophthalmology., 31, 321.

Cantonnet, A., and Filliozat, J. (1934). "Strabismus", 7th ed., trans. M. Coque. Wiseman, London.

Chavasse, F. B. (1939a). " Worth's Squint", Baillière, Tindall, and Cox, London. (1939b). Trans. ophthal. Soc. U.K., 59, 561.

Costenbader, F. D. (1947). Amer. J. Ophthal., 30, 751.

CrITCHETT, G. (1855). Lancet, 1, 479.

DONDERS, F. C. (1864). "On the Anomalies of Accommodation and Refraction of the Eye", trans. W. D. Moore. New Sydenham Society, London.

DuANe, A. (1917). In Fuchs, H. E. “" Text-book of Ophthalmology", 5th ed., trans. and rev. by A. Duane. Lippincott, Philadelphia.

DUKe-ElDER, S. (1932). " Text-book of Ophthalmology”, vol. 1, pp. 1029-30. Kimpton, London.

Feldman, J. B. (1935). Arch. Ophthal., Chicago, 13, 419.

(1941). Ibid., 26, 38.

GeselL, A. L. (1923). "The Pre-school Child from the Standpoint of Public Hygiene and Education ". Houghton, Boston.

and AMATRUDA, C. S. (1947). "Development Diagnosis; Normal and Abnormal Child Development ", 2nd ed. Macmillan, New York and London. ment ". Macmillan, New York.

ment". Macmillan, New York. and Thompson, H. (1938). "The Psychology of Early Growth". Macmillan, New York. and others (1941). "The First Five Years of Life". Macmillan, London. [1940Harper, New York].

Goulden, C. (1935). Trans. ophthal. Soc. U.K., 55, 576.

GRAEFE, A. vON (1854). v. Graefes Arch. Ophthal.,

GuiBor, G. P. (1934). Arch. Ophthal., Chicago, 11, 433.

Helmholtz, H. von (1924). "Treatise on. Physiological Optics". Translation of 3rd German edition, ed. J. P. C. Southall. Optical Society of America. 
Hicks, A. M., and Hosford, G. N. (1935). Arch. Ophthal., Chicago, 13, 1026.

Hitz, J. B. (1941). Amer. J. Ophthal., 24, 1019.

Huxley, A. (1943). "The Art of Seeing". Chatto and Windus, London.

Javal, É. (1864). Pr. Sci. Deux Mondes, 1, 584.

(1868). "Du strabisme dans ses applications à la théorie de la vision". Thèse de Paris.

(1896). "Manuel théorique et pratique du strabisme". Masson, Paris.

(1903). “Entre aveugles". Masson, Paris.

LANCASTER, J. E. (1942). Amer. J. Ophthal., 25, 866.

(1943). Ibid., 26, 463.

LANCASTER, W. B. (1941a). Ihid., 24, 485.

(1941b). Ibid., 24, 619.

(1941c). Ibid., 24, 741.

(1944). Arch. Ophthal., Chicago, 32, 167.

LAW, F. W. (1938). British Journal of Ophthalmology, 22, 193.

LYLE, K., and JACKson, S. (1940). "Practical Orthoptics in the Treatment of Squint ", 2nd ed. Lewis, London. Also 3rd ed. (1949).

Maddox, E. E. (1898). " Tests and Studies of the Ocular Muscles ”. Wright, Bristol.

MANN, D. S. (1943). British Journal of Ophthalmology, 27, 215.

MAYOU, S. (1936). Ibid., 20, 360.

PARINAUD, H. (1899). "Le strabisme et son traitement". Doin, Paris.

Pascal, J. I. (1934). Amer. J. Ophthal., 17, 801.

Pavlov, I. P. (1910). "The Work of the Digestive Glands", trans. by W. H. Thompson, 2 nd ed. Griffin, London.

(1927). "Conditioned Reflexes: an investigation of the physiological activity of the cerebral cortex ", trans. and ed. by G. V. Anrep. Milford, London.

(1935). "Experimental Pathology of the Highest Nervous Activity". Leningrad.

(1928-1941). "Lectures on Conditioned Reflexes", trans. and ed. by W. Horsley Gantt, 2 vols. Lawrence, London.

Pugh, M. A. (1936). "Squint Training". Oxford University Press, London.

RÉmY, A. (1906). "Le diploscope et ses applications". Masson, Paris.

Roth, E. (1947). Amer. J. Ophthal., 30, 748.

ShaAD, D. J. (1938). Arch. Ophthal., Chicago, $20,477$.

SMITH, M. I. (1939). Ibid., 21, 990.

SMITH, PRIESTLEy (1898). Trans. ophthal. Soc. U.K., 18, 17.

Travers, T. àB. (1936). "Concomitant Strabismus"." Pulman, London. (1938). British Journal of Ophthalmology, 22, 577. (1940). Ibid., 24, 58.

Verhoeff, F. H. (1938). Arch. Ophthal., Chicago, 19, 663.

WELlS, D. W. (1912). "The Stereoscope in Ophthalmology. Heterophoria and Incipient Strabismus". New York.

Wheeler, M. C. (1941). Arch. Ophthal., Chicago, 26, 260.

White, J. W. (1944). Amer. J. Ophthal., 27, 977.

WORTH, C. (1903). "Squint: its Cause, Pathology and Treatment". Bale and Danielsson, London. 